Revista

dos Mestrados

Profissionais

ISSN: 2317-0115
O TEXTO, O ARgUMENTO E A AUTORIA CIENTÍfICA.

THE TEXT, THE ARGUMENT AND THE SCIENTIFIC AUTHORSHIP

Denílson Bezerra Marques ${ }^{1}$
Doutor em Sociologia pela UFPE. Prof. Associado do Dept. de Ciências Adm. da UFPE e Docente do quadro permanente do MGP - UFPE

(Mestrado Profissional em Gestão Pública).

Tem concentrado suas pesquisas na área: i) do Planejamento Público; ii) da Sociologia, com ênfase em Sociologia Simétrica e Teoria do Ator-Rede, buscando compreender o fenômeno do conhecimento científico e as formas de relacionamento entre a Sociedade e a Natureza; e iii) da Psicanálise, com ênfase em Psicanálise Organizacional. E-mail: marquesdb@gmail.com
RESUMO: Esta reflexão tem por objetivo problematizar, de maneira introdutória, o fenômeno da autoria em textos científicos no campo da Ciência, de forma geral, e da ciência da Administração de forma particular. Não se trata, porém, de uma reflexão pós-estruturalista ou mesmo estruturalista. A discussão tem como pano teórico as discussões egressas do campo da epistemologia da ciência e do conhecimento científico. Com isso, intenciona-se, apenas, estabelecer arenas epistemológicas distintas, que em rede, produzem algum significado sobre o que venha a ser a intenção do autor do texto científico. Introduz-se, desta forma, o leitor como elemento importante que interfere na autoria do texto, uma vez que este produz seu entendimento particular sobre a mensagem "original". Da mesma forma é introduzido o que chamamos de múltiplo da autoria como um tipo de espelho em que tradição, argumento de autoridade e a própria autoria se encontram.

PALAVRAS-CHAVE: autoria; co-autoria; leitor; argumento.

ABSTRACT: This reflection has for objective to problematizar, in introductory way, the phenomenon of the authorship in scientific texts in the field of Science, general form, and the science of the Administration of particular form. It is not treated, however, of a reflection after-estruturalista or exactly estruturalista. The quarrel has as deep theoretical cloth of the deriving quarrels of the field of the apistemologia of science and the scientific knowledge. With this, intenciona, only, to establish distinct enclosures for bullfighting epistemic, that in net, produces some meaning on what it comes to be the intention of the author of the scientific text. It is introduced, of this form, the reader as important element that it intervenes with the authorship of the text, a time that this produces its particular agreement on "the original" message. In the same way it is introduced what we call multiple of the authorship as a type of mirror where tradition, authority and the proper authorship if they find.

KEYWORDS: authorship; co-authorship; reader; argument. 
Revista

dos Mestrados

Profissionais

ISSN: 2317-0115
Por texto entendamos toda a forma de expressão comunicativa humana, inclusive os atos da fala, que quando transpostos da dimensão oral para a dimensão escrita, assumem a forma de um texto. Por este motivo, utilizaremos a expressão texto com este sentido ampliado.

\section{O TEXTO, O ARGUMENTO E A AUTORIA CIENTÍFICA}

Pensar a produção científica em Administração requer a articulação com diversas outras disciplinas do saber, ao mesmo tempo em que se requer superar pressupostos positivistas em atenção a pressuposto humanistas. Mas como conseguir este feito, uma vez que o estudo da Administração é pautado por uma interpretação positivista? E neste sentido haveria uma interpretação nos textos científicos que por si só expressariam a verdade, não deixando espaço para interpretações distintas. O que discutiremos neste artigo é que o fenômeno da autoria ultrapassa muito esta tradição da área. Que, diga-se de passagem, não lhe é exclusiva. O mesmo também ocorre em outras áreas das humanidades. Pois bem vejamos como esse fenômeno da autoria científica se opera.

Quando analisamos um texto $\underline{1}$ em geral, e os textos científicos em particular, sobretudo de autores que não temos a possibilidade de manter contato, pois não terão acesso a nossos comentários e críticas, ou ainda de autores já falecidos, é preciso ter em mente que nossa atribuição sobre a autoria do texto, é recorrentemente, uma atribuição exógena, ou seja, ad hoc. Com esta afirmação queremos enfatizar que os verdadeiros autores dos comentários feitos são os leitores, e não o próprio autor. São de fato os leitores os que afirmam ser este ou aquele os pontos de vista que estão expressos no texto, e, portanto, a que se destina "sua reflexão", induzindo ou guiando o sentido que "originalmente" o autor atribuiu. Logo, o leitor que se transforma em intérprete, adiciona para si uma nova condição metodológica: a coautoria. Com isso o leitor passa a ser coautor deste texto sobre o qual produziu sua interpretação, e, em certo sentido, alterou sua mensagem original através da atribuição que sua interpretação produziu. Pois bem, o autor não consciente de nossas reflexões e de nossas coautorias, não tem como emitir seu parecer quanto ao juízo que lhe foi atribuído. $\mathrm{O}$ autor não tem como corroborar ou refutar tais atribuições, por simplesmente desconhecer a identidade de seus numerosos leitores. Desta forma assume-se seu parecer como ajustado à explicação produzida pelo leitor que além de intérprete torna-se coautor.

Assim, expressões do tipo: a) não foi exatamente isto que eu quis dizer..., ou; b) sua análise está parcialmente contemplada em minha reflexão..., ou; c) de fato eu afirmei isto, todavia apontando um contexto um pouco diferente ao qual você está me atribuindo..., ou; d) isto não está condizente com o que escrevi..., ou; e) foi exatamente isto que almejei passar..., etc; tornam-se fundamentais para salvaguardar o autor e seu texto. Estes tipos de opiniões e valores emitidos pelo próprio autor, provavelmente não terão os seus leitores. E por não os ter, julgamos sua autoria aquilo que efetivamente foi uma interpretação nossa num primeiro momento, e, num segundo momento uma atribuição. 
Logo, quando dizemos que o autor diz isto, e, ainda, apontamos o local do texto em que tal afirmação é reconhecida (fato este recorrente em textos científicos em que registramos a fonte bibliográfica), de fato, o que está ocorrendo é que estamos patrocinando a coincidência dos significados dos argumentos, e, desta maneira, mesmo que inconscientemente, estamos interferindo no conteúdo objetivo do texto, a partir de nossa impressão e sentidos atribuídos. Como verificar esta situação na Ciência? Não é difícil encontrarmos na literatura científica expressão do tipo: a) A epistemologia do Iluminismo devolveu à humanidade a prerrogativa da liberdade; b) A escola das relações humanas institui a centralidade no indivíduo no paradigma científico das teorias da Administração em substituição ao paradigma da escola científica da Administração; c) O Marketing moderno apresentou aos administradores o fenômeno da miopia em Marketing revolucionando, assim, a pesquisa na área. Mas o que vem a ser liberdade, centralidade no indivíduo ou o fenômeno da miopia em Marketing?

Se observarmos atenciosamente, veremos que a resposta a estas perguntas implica uma autoria própria que buscamos encontrá-la de forma coincidente nos manuais e textos científicos. É esta busca pela coincidência que lastreia uma parte substancial de nossa reflexão aqui neste texto, que apresentamos aos demais pesquisadores e futuros coautores.

Estes movimentos reforçam aspectos, ou detalhes, na obra do autor que o leitor julga haver coincidência entre sua perspectiva e a perspectiva do autor, o que confere tom de "autoridade" ao leitor por estar interpretando de forma "certa" e "inquestionável" a "verdade" que ali se encontra. Ocorrem também nas releituras produzidas pelos leitores, acréscimos ou destaques a problemas, conceituações e mesmo hipóteses que se julgam não presentes na obra do autor. Estes são considerados, então, contribuições. Agora a autoria da obra, e suas consequentes assertivas, mesmo que consensuais, são definitivamente exteriores à obra do autor.

O aspecto consensual ou de "maioria" de interpretações semelhantes, não confere à autoria sua condição endógena, apenas reforça o aspecto exógeno egresso de uma coautoria. Este último aspecto passa agora a incorporar uma condição de legitimação da autoria por "especialistas" no assunto de qualidade intelectual "inquestionável". Latour (2000) chamaria isto, por exemplo, de alistamento de aliados capazes de se comportar como porta-vozes qualificados em rede de sucessivas aberturas e fechamentos de caixas-pretas científicas ou simplesmente fatos científicos.

Com estas observações não estamos colocando como prioritário, nesta discussão, o problema do relativismo - comum nas discussões da história interna da ciência, mas suficientemente superados pela história externa da ciência, como diria Lakatos (1987) - o que num primeiro momento pode até suscitar. Nosso intuito é o de chamar a atenção para outro tipo de fenômeno que chamaremos de múltiplos da autoria. Com 
2 -

Vide Latour (2000)

e Latour e Wo-

olgar (1997). isso, o que buscamos é separar o caráter singular de seu plural, ou seja, todo texto tem seus argumentos natos, próprios, oriundos do próprio autor, mas uma vez que este texto passa a ser interpretado por outros, passa a coexistir com um conjunto de argumentos passageiros, oportunistas, oriundos agora dos distintos intérpretes. $\mathrm{O}$ argumento passageiro ou oportunista, não se constitui uma blasfêmia ou depreciação, assumindo assim um caráter eminentemente negativo ou depreciativo. Pelo contrário, este tipo de argumento, quando legitimado pela maioria dos demais intérpretes, torna-se o núcleo duro do texto (fato científico nos termos latourianos), o que significa ser ele mesmo a "verdadeira" mensagem que o autor queria passar a seus atentos leitores $\underline{\mathbf{2}}$.

Percebamos aqui a dificuldade de se estabelecer com exatidão a exclusividade da autoria do texto para com seu autor. A autoria é ela mesma, uma construção social e política das diversas modalidades interpretativas de um dado texto, e, neste sentido, o conjunto de argumentos é igualmente uma alocação exterior que é empreendida a favor do texto, passando a ser, com isso, a mensagem original do autor do texto.

O que ocorre aqui? O que de fato analisamos e assumimos como aquilo que foi dito pelo autor é na verdade uma construção social, política e histórica, operadas pelos distintos intérpretes sobre como se estabiliza um determinado fato científico. E, neste sentido, atribuições novas sempre surgirão no futuro, "reforçando" a condição de autoria do autor do texto para quem interpreta. Todavia, é preciso não perder de vista esta dimensão, ou seja, a dimensão de um múltiplo da autoria, o que equivale dizer que, há um tipo de texto espelho do texto original para cada intérprete, assim como, há um argumento espelho para cada argumento interpretado. É este espelho que se constitui o próprio texto quando sujeito as interpretações, e, por conseguinte, é este espelho que oportuniza o fenômeno da coautoria, que se reveste de um múltiplo da autoria. Isto equivale dizer que o coautor não se sente autor, e, em assim não se sentido, não sente a influência que sua interpretação exerce sobre a mensagem original do texto que está sob sua análise. Concomitantemente, não percebe que o texto deixou de ser o texto em si mesmo e torna-se um texto em estado indefinidamente "aberto", sujeito às construções e reformulações por todos aqueles que passam a ser seu coautor, os outros intérpretes ou coautores. Em outras palavras, o texto passa a ser aquilo que o fenômeno do múltiplo da autoria produz.

O estado de permanente abertura ou de permanente construção está no sentido de que o múltiplo da autoria nunca se fecha para outros pretensos coautores, e, sempre que ocorre uma nova inclusão ou exclusão de significados e, de cadeias de significância, a mensagem original do "autor" se "reforça" ainda mais. Desta forma, o fenômeno da autoria é de caráter eminentemente social, político, extralinguístico, coletivo, construcionista e a posteriori, e, sua essência não relativista reside na estabilidade que os momentos históricos propiciam a partir de 
$3^{-}$

Temos aqui importantes aproximações com o pensamento de Latour (2000), Latour e Woolgar (1997), como também de Bloor (1991) e de Bachelard (2004) 4 -

Vide Harré (1984). 5 -

Estes interesses podem ser do tipo defendido por Bourdieu (1994) - modelo de competição; ou ainda o que apregoa Habermas (1982) - concebido como consequência da intersubjetividade do conjunto dos cientistas alimentada por prerrogativas capitalistas. 6 -

Sobre este tema vide Knorr-Cetina (2003). 7 -

Vide Althusser (1990). uma interpretação dominante ou hegemônica pertinente ao fenômeno do múltiplo da autoria em momentos históricos, sociais e políticos específicos $\underline{3}$.

Com isto, é nossa intenção colocar aqui, de forma clara, que existe uma organização do pensamento social que está historicamente compartilhada e consentida, a que chamamos de "ideologia geral". A ideologia geral é uma característica da sociedade num dado momento histórico e exprime-se tanto pela preferência por certas ideias teóricas, artísticas ou políticas, por parte dos cidadãos de forma geral e dos cientistas de forma particular, como também através dos interesses de classes dos cidadãos, capitalistas e empresários e, revelam-se nas formas como eles arquitetam os edifícios econômicos e as instituições supra estruturais da comunidade a que pertence $\underline{4}$. As preferências científicas, artísticas, gerenciais e políticas conduzem ao aparecimento de determinados tipos de ideias que, em termos bastante amplos, podem ver-se como relacionadas com os interesses de dada comunidade científica, política e empresarial em dado momento histórico $\underline{\mathbf{5}}$.

Todo nosso esforço em produzir esta breve explicação tem por objetivo instrumentalizar os leitores deste texto, que poderão se constituir em coautores, reforçando, assim, o caráter de múltiplos da autoria, juntamente com o autor, sobre as naturezas sociais, históricas e políticas da análise que se empreende a partir da produção de qualquer tipo de texto no campo científico de forma geral e da ciência da administração de forma particular.

Devemos sempre ter a certeza de que nossa interpretação só será considerada apta à condição e ao status de múltiplo da autoria, se ela se consubstanciar legitimada por outros leitores, que foram incluídos no campo dos coautores, cuja condição seja equivalente a nossa, ou seja, o autor está impossibilitado de emitir seu parecer quanto à precisão das análises, e, por conseguinte, quanto à condição de acatar ou de refutar as atribuições que lhes foram feitas. Assim, quando analisarmos os diversos textos científicos, buscando o conjunto dos argumentos que lhes formam a espinha dorsal, ao fazermos isto, estamos buscando, como unidade metodológica, o espelho dos argumentos que atribuímos. Logo, estamos buscando uma compreensão do sentido destes argumentos, a partir dos contextos sociais, políticos, gerenciais e históricos que estabilizaram a temática objeto de nossa investigação nos distintos campos e arenas transepistêmica da ciência $\underline{\mathbf{6}}$.

Sociedade (a parte do conceito não científico $\underline{7}$ cujo conjunto de coautores acredita ter estabilizado em arena epistemológica própria da ciência), Ciência e Conhecimento Científico possuem internamente em cada termo uma rede epistemológica que produz entrecruzamentos variados, com infindáveis fontes de pressão e distintos pontos nodais em que se estabilizam os inumeráveis fatos científicos que daí decorre. Administração: ciência ou arte? São questionamentos encontrados nos textos introdutórios ao estudo da Administração que orientam a interpretação do leitor ou do estudante a se inclinar mais por um caminho 
que por outro. Como então controlar a autoria e a autoridade de um texto produzido, senão pela lógica inerente desta rede que se desenvolve em epistemologias interconectadas entre si?

Pulando para outra arena transepistêmica (campo da teoria do discurso ou pós-estruturalismo), cabe aqui assinalar uma importante implicação, oriunda de linguistas como Pêcheux (1990) e Foucault (2002), que, por exemplo, pode perfeitamente ser encaixada em nossa reflexão até aqui produzida. Trata-se do avizinhamento às categorias de interdiscurso, para o primeiro e de formações discursivas, para o segundo. A aproximação que aqui nos importa refere-se que, à semelhança do que ocorrem com os discursos, os argumentos científicos nascem a partir de um conjunto de outros argumentos (científicos ou não), que lhes são anteriores. A semelhança para por aqui, pois continua havendo um autor, ao contrário do que preconiza o estruturalismo e o pós-estruturalismo, que postulam sua morte (Santos, 2000).

O autor do argumento continua existindo uma vez que seu postulado está localizado na fala de um indivíduo, logo, na análise do argumento. $\mathrm{O}$ par argumento-indivíduo difere do par discurso-sujeito assujeitado da análise do discurso. A ressalva que se faz necessária aqui, é que estes outros argumentos são argumentos que emergem do múltiplo da autoria, logo, são argumentos espelhos do argumento original oficializado por um leitor legitimado por sua comunidade direta e pela ideologia geral. Mesmo que esteja pregando um contraponto, um complemento, ou mesmo, uma oposição, continua sendo um argumento espelho, pois se trata de uma interpretação de outros indivíduos.

A noção de interdiscurso e de universo do discurso tem seu equivalente em Toulmim (2001/1958, p. 20), quando este se utiliza da categoria campos do argumento. Por campo dos argumentos, Toulmim assinala que:

"dois argumentos pertencem ao mesmo campo quando os dados e as conclusões em cada um dos dois argumentos são, respectivamente, do mesmo tipo lógico; diz-se que eles vêm de campos diferentes quando o suporte ou as conclusões de cada um dos dois argumentos não são do mesmo tipo lógico."

Observemos surgir aqui, embora tangencialmente, o mesmo fenômeno que estamos destacando, ou seja, dentro deste campo argumentativo, não há como negar uma atribuição externa que classifique o argumento neste ou naquele campo. Logo este argumento, é um argumento espelho de um coautor inconsciente da condição de sua coautoria. Isto não exclui, ou não prescinde de relevância a identificação do campo do argumento, apenas evoca a natureza exógena do argumento como parte constitutiva de sua análise.

Retornando à nossa arena epistemológica, a arena da Ciência (em seus aspectos gerais) e da Ciência da Administração (em seu aspecto particular), vemos que os cientistas ou os pesquisadores dos fenôme- 
8

Vide aqui Merleau-Ponty (2014) nos administrativos, são treinados em certos caminhos e seus interesses e expectativas são endossadas com uma estrutura de crença e de verdade socialmente legitimados, que dificulta ver o que estiver fora dela (estrutura).

A crença científica, de certa forma, recria as condições do sagrado e do profano, o que equivale dizer que imputamos incognoscibilidade à dimensão da coautoria ou ao que chamamos aqui de múltiplos da autoria. Este se torna algum tipo de dimensão "sagrada" em função de sua não problematização (ou do estranhamento em se problematizar tal reflexão). O que implica dizer, que a postura, supostamente "isenta", da leitura produzida pelos cientistas e pesquisadores administrativos sobre o próprio texto científico, não se aplica. Devemos, então, desenhar uma formulação teórica capaz de ultrapassar a dimensão em que o autor se constitui como o único a possuir autoridade sobre o texto e alcançar a dimensão em que o texto, a depender do momento histórico e da comunidade de cientistas, absorve seus leitores como coautores de si próprio. Mas o texto original e seu autor continuam existindo em uma dimensão temporal e estrutural paralela ao texto "modificado" pelos seus agora coautores e não mais meros leitores. Outrossim, ambos os lados (texto original e texto modificado) alternam suas posições relativas de forma contínua e ininterrupta, tendo como parâmetro, as contingências da vida cotidiana e as necessidades políticas, artísticas e sociais particulares de cada cientista, ou de cada comunidade científica em momento histórico próprio.

Não é minha intenção neste texto finalizar este debate. Almeja-se tão somente realçar tal problematização como um eixo investigativo no campo da Ciência da Administração, capaz de provocar a reflexão no seio da comunidade de cientistas que este texto possa alcançar. Busca-se, desta forma, um guia para a reflexão teórica que nos propomos aqui. Com isso busca-se articular alguns possíveis diálogos que possam nos ajudar a melhor compreender a natureza da autoria de um texto científico.

Cabe aqui enfatizar que o fato de continuar havendo um texto original, assim como a possibilidade da existência em paralelo com este espectro modificado implica uma reflexão que pressupõe o abandono do espaço da representação unidimensional para dar lugar a um espaço de representação multidimensional articulado em redes de arenas transepistêmicas. Redes estas que conforme Knorr-Cetina (2003) mostram como os cientistas criam conhecimentos e determinam como nós sabemos o que sabemos.

Este novo espaço torna o debate da autoria um tipo de questionamento que autoriza o desconforto metafísico proveniente desta nova arena epistemológica. Arena esta pautada por uma dimensão de presença e de não-presença em que autores e texto original coexistem com coautores e textos modificados. Assim sendo quando realçamos a dimensão da presença, nela está inserida a dimensão da não-presença, e vice e versa $\underline{8}$. Com isto é preciso compreender que não há uma oposi- 
ção ou um antagonismo. É antes, uma compreensão do ajuntamento de realidades materialmente racionais fruto de como se dá a interconexão em pontos nodais distintos da rede de epistemologias que constitui a Ciência moderna, inclusive a ciência da Administração.

É preciso compreender o fenômeno do múltiplo da autoria através de uma presença que comporta uma não-presença. Parafraseando aqui Merleau-Ponty não há uma presença dissociada de uma não-presença, assim como o seu contrário. Estes se tornam um ou outro em conformidade com a variação qualitativa no interior da perspectiva argumentativa e da práxis de dada comunidade científica em dado momento histórico, social e político, cujas modificações estruturais conferem lógica própria, potencializando, assim, as possibilidades de modelagem e de alistamento contínuo de novos coautores.

De forma conclusiva o que provocamos aqui, enquanto reflexão no campo científico em geral e no campo da Ciência Administrativa em particular, é que todo texto científico descreverá pelo menos três funções básicas, que derivamos do Programa Forte de Bloor (1991):

- Função discriminatória: nossas crenças estão subordinadas a regras e a níveis de tipificações das coisas.

- Função retórica: há em nosso saber geral e científico um componente social que nos possibilita "subverter" as regras de nossas crenças sobre as coisas do mundo (ordem cognitiva). $\mathrm{O}$ verdadeiro e o falso são discursos legitimados por uma autoridade imanente do mundo social, que se propõem entender nossa submissão ao poder do mundo natural.

- Função materialista: nós assumimos que nossa existência se observa em um ambiente comum e externo, cuja estrutura de funcionamento determina sua estabilidade e as leis que nos possibilitam convergir a um mesmo objeto.

Em suma, quando nós, coautores, interpretamos um texto e com isso afirmamos algo sobre o que é ou deixa de ser um fato científico em qualquer arena transepistêmica da ciência, estamos imputando significados externos ao texto ao mesmo tempo em que patrocinamos a coincidência de nossa interpretação com a suposta interpretação, ou intenção, de quem assina o texto científico. O múltiplo da autoria que emerge produz, por trás da expressão que atribuímos a teorias e fatos científicos - corroborados ou falseados, novos pontos nodais na rede já estabelecida composta de significado e da cadeia de significância. Com isto estamos produzindo uma atribuição significativa que se mantém devido à tradição (ideologia geral), legitimada, no convívio com os demais cientistas contemporâneos. Desta forma, toda nossa tradição é sempre uma tradição presente que "cria" e que valida o passado através de textos, de argumentos e de autorias empreendidas historicamente e legitimada por cada cientista, por cada pesquisador do fenômeno administrativo, por cada um de nós. 
É este texto, repleto de "autores", que assumimos como nosso texto científico à partir de nossa interpretação. E, esta é uma das grandezas da Ciência humanizada e não positivada, a autoridade que cada cientista possui em atribuir significados para submetê-lo ao julgamento dos demais cientistas, quer seja corroborando quer seja falseando hipóteses; ou ainda, quer seja produzindo pesquisa teórica, quer seja produzindo pesquisa empírica. A Ciência de forma geral e a ciência da Administração de forma particular são, portanto, aquilo que autorizamos como coautores dos textos estudados, interpretados e utilizados para o ensino e para a pesquisa em Administração. Com isso legitimamos o que somos: autores de textos científicos, ou simplesmente cientistas da administração. 


\section{REFERÊNCIAS}

ALTHUSSER, Louis. (1990), Sobre a reprodução. Petrópolis, RJ: Vozes.

BLOOR, David. (1991), Knowledge and Social Imagery.

Chicago - USA, The University of Chicago Press.

BACHELARD, Gaston. (2004), Ensaio sobre Conhecimento Aproximado. Rio de Janeiro, Contraponto.

BOURDIEU, Pierre. (1994), "A Procura de uma Sociologia da Prática", in Renato Ortiz (org.), Ciências Sociais - Sociologia, São Paulo, Ática.

FOUCAULT, Michel (2002), A Arqueologia do Saber. Rio de Janeiro, Forense Universitária.

HARRÉ, Rom. (1984), As Filosofias da

Ciência. Lisboa - Portugal, Edições 70.

HABERMAS, Jürgen. (1982), Conhecimento $e$ Interesse. Rio de Janeiro, Zahar Editores.

KNORR-CETINA, Karin. (2003), Epistemic Cultures. Massachusetts, Harvard University Press.

Lakatos, Imre. (1987), Historia de las Ciencias y sus Reconstrucciones Racionales. Madrid, Tecnos.

LATOUR, Bruno. (2000), Ciência em Ação. São Paulo, Editora UNESP.

\& WOOLGAR, Steve. (1997), A Vida de

Laboratório. Rio de Janeiro, Relume Dumará.

MERLEAU-PONTY, Maurice. (2014), O Visivel e o Invisivel. São Paulo, Perspectiva.

PÊCHEUX, M. et al. (1990). Discurso - estrutura ou acontecimento? Campinas - SP, Pontes.

SANTOS, Boaventura de S. (2000), A Crítica da Razão Indolente: contra o desperdício da experiência. São Paulo, Cortez.

TOULMIN, Stephen (1958/2001). O Uso do Argumento. São Paulo, Martins Fontes. 